- SPECIAL ISSUE

- Published: 19 June 2020

\title{
Image Similarity Estimation Based on Ratio and Distance Calculation between Features
}

- R. P. Bohush,

- S. V. Ablameyko,

- E. R. Adamovskiy \&

- D. Savca

Pattern Recognition and Image

Analysis volume 30, pages147-159 (2020)Cite this article

- 164 Accesses

- 3 Citations

- Metricsdetails Abstract

Some similarity functions for comparing the features of objects in the processing of static images and video sequences are proposed. These functions provide the possibility to find the normalized similarity value and are determined by calculating the ratios between the minimum and maximum values for all the pairs of analyzed features. To find the complex value characterizing the similarity of compared images as a whole, the summation or multiplication of calculated ratios is used. It is proposed to take into account the distances between features for such types of calculations. Some results of experimental studies on the comparison of the qualitative characteristics of similarity functions, their robustness against different types and levels of noises, and the possibility of the precise localization of objects on an image for the case when the brightness levels of pixels are used as features are presented.

This is a preview of subscription content, access via your institution. 


\section{REFERENCES}

1. 1

R. C. Gonzalez and R. E. Woods, Digital Image

Processing, 3rd ed. (Prentice Hall, Upper Saddle River, NJ , 2008; Tekhnosfera, Moscow, 2012).

2. 2

R. Klette, Concise Computer Vision. An Introduction into Theory and Algorithms (Springer, London,

2014); Computer Vision. Theory and Algorithms (DMK Press, Moscow, 2019) [Russian translation].

3. 3
A. A. Goshtasby, "Similarity and dissimilarity measures," in Image Registration. Principles, Tools and Methods, Advances in Computer Vision and Pattern Recognition (Springer, London, 2012), Chapter 2, pp. 7-66.

4.4
B. Zitová and J . Flusser, "Image registration methods: a survey," Image Vision Comput. 21(11), 977- 1000 (2003).

\section{Article Google Scholar}

5. 5

S.-H. Cha, "Comprehensive survey on distance/ similarity measures between probability density functions," Int. J . Math. Models Methods Appl. Sci. 1(4), 300- 307 (2007). 


\section{Google Scholar}

6. 6

M. Rezaei and P. Fränti, "Set matching measures for external cluster validity," IEEE Trans. Knowl. Data Eng. 28 (8), 2173- 2186 (2016).

\section{Article Google Scholar}

7. 7

V. Gesù and V. Starovoitov, "Distance-based functions for image comparison," Pattern Recogn. Lett. 20 (2), 207214 (1999).

\section{Article Google Scholar}

8.8

L. Wang, Y. Zhang, and J . Feng, “On the Euclidean distance of images," IEEE Trans. Pattern Anal. Mach. Intell. 27 (8), 1334- 1339 (2005).

\section{Article Google Scholar}

9.9
A. Nakhmani and A. Tannenbaum, "A new distance measure based on generalized Image Normalized Cross- Correlation for robust video tracking and image recognition," Pattern Recogn. Lett. 34 (3), 315- 321 (2013).

\section{Article Google Scholar}


N. G. Zagoruiko, I. A. Borisova, V. V. Dyubanov, and O. A. Kutnenko, "A quantitative measure of compactness and similarity in a competitive space," J . Appl. Ind. Math. 5 (1), 144- 154 (2011).

\section{Article Google Scholar}

11. 11

G. Lv, ' $1 \mathrm{~m}_{\mathrm{p}}$ : A novel similarity measure for matching local image descriptors," IEEE Access 6, 55315- 55325 (2018).

\section{Article Google Scholar}

12. 12

J --I. Kim, Ch.-U. Hyun, H. Han, and H.-C. Kim,

"Evaluation of matching costs for high-quality sea-ice surface reconstruction from aerial images," Remote Sens. 11(9), 1055- 1072 (2019).

\section{Article Google Scholar}

13. 13

R. Bohush and I. Zakharava, "Robust person tracking algorithm based on Convolutional Neural Network for indoor video surveillance," in Pattern Recognition and Information Processing, PRIP 2019, Ed. by S. V. Ablameyko, V. V. Krasnoproshin, and M. M. Lukashevich, Communications in Computer and Information Science (Springer, Cham, 2019), Vol. 1055, pp. 289-300. 


\section{Google Scholar}

14. 14

S. V. Voronov and A. G. Tashlinskii, "Efficiency analysis of information theoretic measures in image registration," Pattern Recogn. Image Anal. 26 (3), 502- 505 (2016).

\section{Article Google Scholar}

15. 15

S. V. Voronov and A. G. Tashlinskii, "Analysis of objective functions in the problem of estimating mutual geometric deformations of images," Pattern Recogn. Image Anal. 24 (4), 575- 582 (2014).

\section{Article Google Scholar}

16. 16

M. M. Deza and E. Deza, Encyclopedia of

Distances (Springer, Berlin, Heidelberg, 2009).

\section{Book Google Scholar}

17.

17

S. Chambon and A. Crouzil, "Dense matching using correlation: new measures that are robust near occlusions," in Proc. British Machine Vision Conference (BMVC 2003) (East Anglia, Norwich, UK, 2003), Vol. 1, pp. 143- 152.

18. 18 
J . Nakamura (ed.), Image Sensors and Signal Processing for Digital Still Cameras (CRC Press, Boca Raton, 2005).

\section{Google Scholar}

Download references

\section{Author information}

\section{Affiliations}

1. Polotsk State University, 211440, Novopolotsk, Republic of Belarus

R. P. Bohush \&E. R. Adamovskiy

2. Belarusian State University, 220030, Minsk, Republic of Belarus

S. V. Ablameyko

3. United Institute of Informatics Problems, National Academy of Sciences of Belarus, 220012 , Minsk, Republic of Belarus

S. V. Ablameyko

4.Petroleum and Gas University of Ploiesti, 100680, Ploiesti, Romania

D. Savca

Corresponding authors

Correspondence to R. P. Bohush, S. V. Ablameyko, E. R. Adamovskiy or D. Savca.

Ethics declarations

The authors declare that they have no conflicts of interests. Additional information

Rykhard Bohush graduated from the Polotsk State University in 1997. He received a PhD in the field of information processing at the Institute of Engineering Cybernetics of the National Academy of Sciences of Belarus in 2002. He is head of the Department of Computer Systems and Networks of the Polotsk State University. His scientific 
interests include image and video processing, object representation and recognition, intelligent systems, and digital steganography.

Sergey Ablameyko was born in 1956 and received a DipMath in 1978, PhD in 1984, DSc in 1990, and Professor in 1992. He is a professor at the Belarusian State University, member of the Editorial Board of Pattern Recognition Letters, Pattern Recognition and Image Analysis and many other international and national journals; Senior Member of IEEE; Fellow of IAPR; Fellow of the Belarusian Engineering Academy; Academician of the National Academy of Sciences of Belarus; Academician of the European Academy; and more. He was the First Vice-President of the International Association for Pattern Recognition IAPR (2006- 2008), and President of the Belarusian Association for Image Analysis and Recognition. His scientific interests are image analysis, pattern recognition, digital geometry, knowledge-based systems, geographical information systems, and medical imaging.

Egor Adamovskiy graduated from the Polotsk State University in 2017. He received a degree of Master of Engineering Sciences in the field of information security in 2019, and was a postgraduate student and engineer at the Computer Systems and Networks Department of the Polotsk State University. His research interests include image processing, information security systems, and technical channels for information leakage.

Daniel Savca was born in 1996. He is a magistrate student of the Gas and Petroleum University of Ploiesti, Romania, with a 
Bachelor's degree in the field of automation and applied informatics. His scientific interests include self-control systems, image processing, and advanced automation.

Translated by E. Glushachenkova Rights and permissions

Reprints and Permissions

About this article

Cite this article

Bohush, R.P., Ablameyko, S.V., Adamovskiy, E.R. et al. Image Similarity Estimation Based on Ratio and Distance Calculation between Features. Pattern Recognit. Image Anal. 30, 147-159 (2020). https://doi.org/10.1134/S1054661820020030

Download citation

- Received07 January 2020

- Revised14 January 2020

- Accepted16 January 2020

- Published19 June 2020

- Issue DateApril 2020

- DOI https://doi.org/10.1134/S1054661820020030 Keywords:

- comparison and discovery of images

- similarity functions

https://doi.org/10.1134/S1054661820020030 